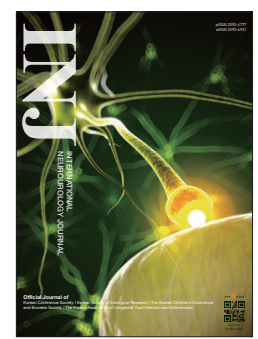

\title{
Alpha-1 Adrenergic Receptor Blockers for the Treatment of Lower Urinary Tract Symptoms in Women: A Systematic Review and Meta-Analysis
}

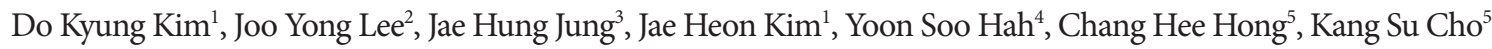 \\ ${ }^{1}$ Department of Urology, Soonchunhyang University Hospital, Soonchunhyang University College of Medicine, Seoul, Korea \\ ${ }^{2}$ Department of Urology, Severance Hospital, Urological Science Institute, Yonsei University College of Medicine, Seoul, Korea \\ ${ }^{3}$ Department of Urology, Institute of Evidence Based Medicine, Yonsei University Wonju College of Medicine, Wonju, Korea \\ ${ }^{4}$ Department of Urology, Daegu Catholic University Medical Center, Daegu, Korea. \\ ${ }^{5}$ Department of Urology, Gangnam Severance Hospital, Urological Science Institute, Yonsei University College of Medicine, Seoul, Korea
}

Purpose: To assess the effectiveness of alpha-1 adrenergic receptor blockers (a1-blockers) in the treatment of female lower urinary tract symptoms (LUTS).

Methods: A literature search was conducted using the PubMed/MEDLINE, Embase, and Cochrane Library databases. Fourteen studies with 1,319 patients were ultimately included. The study comprised 2 analyses: a comparison of urinary symptom scores, maximal flow rate (Qmax), and postvoid residual (PVR) urine volume before and after a1-blocker administration in 8 prospective, open-label studies and 5 randomized clinical trials (RCTs); and an evaluation of the same variables in al-blocker and placebo groups in 4 RCTs.

Results: The first meta-analysis showed that, following treatment, patients exhibited statistically significant symptom relief (mean difference $[\mathrm{MD}],-5.85 ; 95 \%$ confidence interval [CI], -7.71 to -3.99 ; $\mathrm{P}<0.00001)$, increased Qmax (MD, $3.67 \mathrm{~mL} / \mathrm{sec}$; $95 \% \mathrm{CI}$, 2.76-4.59 mL/sec; P<0.00001), and decreased PVR volume (MD, -28.46 mL; 95\% CI, -34.99 to $-21.93 \mathrm{~mL} ; \mathrm{P}<0.00001$ ). In the second meta-analysis, a1-blockers demonstrated significant symptom relief relative to placebo (MD, $-1.60 ; 95 \% \mathrm{CI},-2.68$ to $-0.51 ; \mathrm{P}=0.004)$. However, no significant differences were observed in $\mathrm{Qmax}(\mathrm{MD}, 0.05 \mathrm{~mL} / \mathrm{sec} ; 95 \% \mathrm{CI},-0.74$ to $0.83 \mathrm{~mL} / \mathrm{sec}$, $\mathrm{P}=0.91)$ and PVR (MD, $-8.10 \mathrm{~mL} ; 95 \% \mathrm{CI},-32.32$ to $16.12 \mathrm{~mL}, \mathrm{P}=0.51$ ) between the $\alpha 1$-blocker and placebo groups.

Conclusions: These analyses suggest that $\alpha 1$-blockers are effective in the treatment of female LUTS patients. However, the effect of a1-blockers on female LUTS should be assessed according to the underlying cause, and the role of al-blockers in combination therapy with other drugs should also be investigated.

Keywords: Alpha-adrenergic antagonists; Lower urinary tract symptoms; Voiding dysfunction; Women; Meta-analysis

- Conflict of Interest: No potential conflict of interest relevant to this article was reported.

\section{- HIGHLIGHT}

- Alpha 1-blocker is effective in the treatment of female lower urinary tract symptoms. It showed significant symptom relief compared to placebo, however there was no differences in maximal flow rate and postvoid residual between the a1-blocker and placebo groups.

Corresponding author: Kang Su Cho (iD https://orcid.org/0000-0002-3500-8833 Departments of Urology, Gangnam Severance Hospital, Yonsei University College of Medicine, 211 Eonju-ro, Gangnam-gu, Seoul 06273, Korea E-mail: kscho99@yuhs.ac / Tel: +82-2-2019-3471 / Fax: +82-2-3462-8887 Submitted: August 16, 2018 / Accepted after revision: November 5, 2018 (c) (i) (3) This is an Open Access article distributed under the terms of the Creative Commons Attribution Non-Commercial License (http://creativecommons.org/licenses/by-nc/4.0/) which permits unrestricted non-commercial use, distribution, and reproduction in any medium, provided the original work is properly cited. 


\section{INTRODUCTION}

The European Urological Association guidelines suggest that, relative to placebo, alpha-1 adrenergic receptor blockers ( $\alpha 1$ blockers) reduce urinary symptoms and increase maximal flow rate (Qmax) in men with lower urinary tract symptoms (LUTS) [1]. These agents increase smooth muscle relaxation in the prostate and bladder neck. They constitute the first-line drug treatment of male LUTS due to their rapid onset of action, satisfactory efficacy, and acceptable safety profiles.

Voiding dysfunction in women is defined by the International Continence Society and International Urogynecological Association as abnormally slow and/or incomplete urination diagnosed based on symptoms and urodynamic studies [2]. The overall prevalence of female voiding dysfunction is estimated to be between 3\% and 39\% [3,4]. However, considering the present lack of standardized diagnostic criteria and clinical guidelines, female LUTS is likely overlooked and underestimated. Moreover, the pathophysiological mechanism of female LUTS remains unclear [5].

Although not officially registered for the treatment of female LUTS [6], a1-blockers have been used to alleviate LUTS in women based on their presumed activity in the relief of functional bladder outlet obstruction [7]. In part, the current use of a1-blockers for female LUTS is based on their remarkable effects in the treatment of male LUTS [8]. Published clinical trials evaluating the use of a1-blockers for female LUTS have remained limited in prevalence and participation and have produced contradictory results. The lack of well-designed randomized clinical trials (RCTs) further limits meaningful conclusions. Thus, the authors in the present study conducted a systematic review and meta-analysis assessing the effect of $\alpha 1$ blockers on female LUTS to address some of the current controversies and to obtain additional statistical information.

\section{MATERIALS AND METHODS}

This systematic review was registered in PROSPERO (CRD42 018096181).

\section{Search Strategy}

The authors in the present study conducted computerized bibliographic searches of the PubMed/MEDLINE, Embase, and Cochrane Library databases up to April 2018. The search terms included "female or women," "alpha blocker," "lower urinary tract symptoms," "overactive bladder," "bladder outlet obstruction," "urinary incontinence," and relevant variants. Conference and meeting abstracts were excluded even if they otherwise met the eligibility criteria. The searches identified 482 candidate articles. Two authors (DKK and YSH) independently reviewed the titles and abstracts based on the inclusion criteria and subsequently reviewed the identified articles.

\section{Trial Inclusion Criteria and Exclusion Criteria}

Following the Preferred Reporting Items for Systematic Reviews and Meta-Analyses (PRISMA) guidelines, the eligibility of each study was evaluated using the PICOS (participants, interventions, comparators, outcomes, and study design) method [9]. The authors in the present study defined the study population as female patients with a clinical diagnosis of LUTS and the intervention as a1-blocker treatment. Where appropriate, the placebo was defined as the comparator. The following outcomes were analyzed: urinary symptom score (International Prostate Symptom Score [IPSS] or American Urological Association Symptom Score [AUASS]), Qmax, and postvoid residual (PVR) urine volume. The inclusion criteria were: RCT or prospective design, nonanimal research, female patients with a clinical diagnosis of LUTS, use of a1-blockers, and reported values for IPSS or AUASS scores, Qmax, and PVR urine volume.

The exclusion criteria were: retrospective design, the combination of $\alpha 1$-blockers with other drugs (e.g., anticholinergics or M-cholinolytics), and studies including only elderly women (mean age $>70$ years).

\section{Data Extraction}

Two authors (DKK and YSH) reviewed the full articles and extracted the data from each study independently. Any conflicts in the extracted data were resolved through consensus. The extracted data included study design details, inclusion and exclusion criteria, randomization, participant demographics, treatment characteristics (regimen, dosage, and duration), measured outcomes (IPSS or AUASS, Qmax, and PVR urine volume), and results (mean difference $[\mathrm{MD}]$ and standard deviation $[\mathrm{SD}]$ ).

\section{Assessment of Study Quality}

The design and implementation of RCTs were assessed for the risk of bias according to recent meta-analysis guidelines [10,11]. The risk of bias assessment included examination of the use of random sequence generation, allocation concealment, blinding of participants and researchers, blinding of outcome assess- 
ment, incomplete outcome data, and selective reporting. For prospective studies, the quality of the included clinical trials was evaluated according to the methodological index of the Downs and Black scale using 5 major assessment categories: reporting, external validity, bias, confounding, and power [12].

The authors of the present study evaluated the certainty of comparisons using the Grading of Recommendations, Assessments, Developments, and Evaluation (GRADE) system, which provides a systematic approach to the evaluation of the quality of evidence and strength of recommendations [10] through assessments of the following criteria: methodology, precision, consistency, directness, and risk of publication bias. Based on these criteria, the authors in the present study assessed only direct evidence of pairwise meta-analysis by classifying the quality of evidence on a 4-level scale as high, moderate, low, and very low.

\section{Statistical Analysis}

Changes in LUTS outcomes were measured by IPSS or AUASS, Qmax, and PVR urine volume values, which were recorded as continuous data. Mean and SD values were extracted from all studies except for that published by Lee et al. [5], which presented the results as median and interquartile range. The authors in the present study subsequently calculated the mean and SD values using a known statistical method $[13,14]$. Pooled MDs for pre- and posttreatment values and $95 \%$ confidence intervals (CIs) were calculated for continuous variables. For RCTs, pooled MDs for treatment and placebo group values were calculated along with $95 \%$ CIs. Adverse events were compared between al-blocker and placebo groups using pooled odd ratios (ORs) for dichotomous data across studies. The meta-analyses were performed using the random-effects model of DerSimonian and Laird to obtain pooled overall MDs with 95\% CIs for outcomes [15].

Statistical heterogeneity was assessed using the $\mathrm{I}^{2}$ value and the chi-square test. A Cochran Q statistic $\mathrm{P}<0.05$ or $\mathrm{I}^{2}>50 \%$ indicated the presence of statistically significant heterogeneity. The authors in the present study assessed the stability of the results by sequentially excluding each included study as a sensitivity analysis.

Funnel plots and the Egger test were used to evaluate smallstudy effects, with more than 10 studies included in the analysis. A comprehensive meta-analysis was conducted to investigate potential publication bias. The results are displayed using a funnel plot, with the study size shown on the $y$-axis as a function of the effect size on the $x$-axis. Symmetry reversal funnel

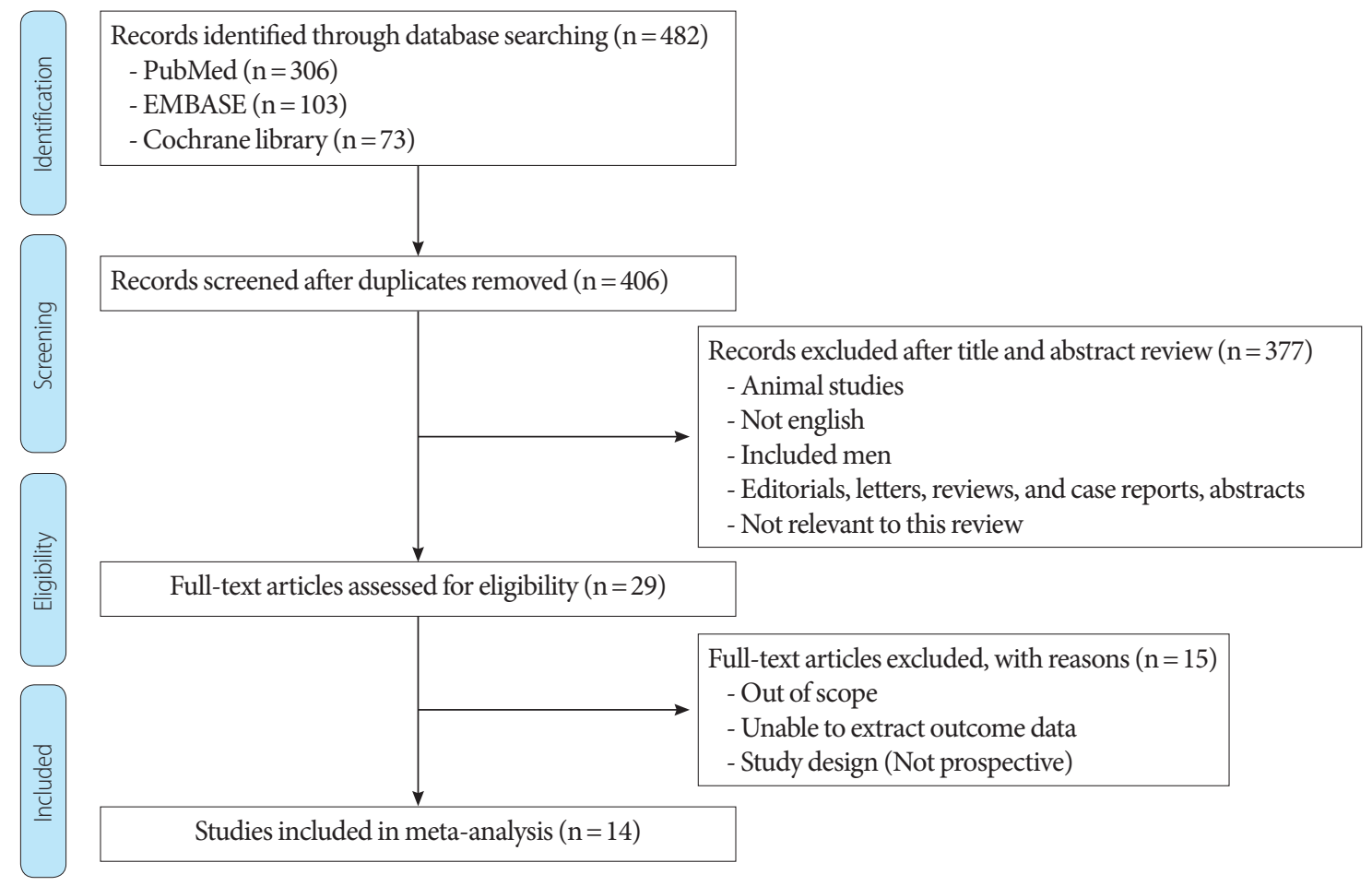

Fig. 1. PRISMA (Preferred Reporting Items for Systematic Reviews and Meta-analysis) flowchart. Chart presenting the flow of information through the different phases of the systematic review, together with the utilized exclusion criteria. 
diagrams did not show significant publication bias, which is indicated by distortion and asymmetry of the inverted funnel plots. P-values $<0.05$ from the Egger test signaled statistically significant publication bias.

The meta-analysis was performed using Review Manager v.5.1 (The Nordic Cochrane Center, The Cochrane Collaboration, Copenhagen, Denmark, 2008). All P-values were 2-sided, and, except for the test of discrepancy, $\mathrm{P}$-values $<0.05$ were considered to indicate a statistically significant result.

\section{RESULTS}

\section{Systematic Review Process}

The authors in the present study used the PRISMA framework to analyze and summarize our systematic analysis and meta-review process (Fig. 1). Only published studies were included to minimize publication bias. The initial database searches identified 482 articles, which were reduced to 406 following duplicate removal. Subsequently, title and abstract review eliminated 377 articles, with only trials published in English included in the present study. An analysis of the remaining full-text articles with respect to the inclusion criteria resulted in the final selection of 14 studies (Table 1 ) with a total of 1,319 patients $[5,6,16$ 27]. Of these studies, 6 were RCTs and 8 were open-label prospective studies. The al-blockers used in these studies included alfuzosin, tamsulosin, and terazosin. The duration of treatment ranged from 4 to 12 weeks across all studies. In all publications, urinary symptom scores were assessed using the IPSS or AU-

Table 1. Characteristics of the selected studies

\begin{tabular}{|c|c|c|c|c|c|c|c|}
\hline Study & Design & $\begin{array}{c}\text { No. of } \\
\text { participants }\end{array}$ & $\begin{array}{l}\text { Alpha-blocker dose } \\
\text { (mg/day) }\end{array}$ & $\begin{array}{l}\text { Treatment } \\
\text { period }\end{array}$ & $\begin{array}{l}\text { Comparator } \\
\text { (mg/day) }\end{array}$ & $\begin{array}{c}\text { Mean } \\
\text { age (yr) }\end{array}$ & Outcomes \\
\hline $\begin{array}{l}\text { Athanasopoulos, } \\
2009 \text { [16] }\end{array}$ & Open-label prospective & 25 & Alfuzosin $10 \mathrm{mg}$ & 8 Weeks & None & 53 & Qmax, PVR \\
\hline Chang, 2006 [17] & Open-label prospective & 71 & Tamsulosin $0.2 \mathrm{mg}$ & 8 Weeks & None & 54.4 & $\begin{array}{l}\text { IPSS, Qmax, } \\
\text { PVR }\end{array}$ \\
\hline Chang, 2008 [18] & Open-label prospective & 97 & Tamsulosin $0.2 \mathrm{mg}$ & 6 Weeks & None & 63.8 & $\begin{array}{l}\text { IPSS, Qmax, } \\
\text { PVR }\end{array}$ \\
\hline Costantini, 2009 [19] & Open-label prospective & 63 & Tamsulosin $0.4 \mathrm{mg}$ & $\geq 4$ Weeks & None & 60.2 & Qmax, PVR \\
\hline $\begin{array}{l}\text { Hajebrahimi, } \\
2011[20]\end{array}$ & RCT & 40 & Tamsulosin $0.4 \mathrm{mg}$ & 12 Weeks & $\begin{array}{r}\text { Prazosin } \\
1-2 \mathrm{mg}\end{array}$ & $\begin{array}{l}\text { Tamsulosin, } \\
\text { 47.35; prazosin, } \\
49.4\end{array}$ & Qmax, PVR \\
\hline Kim, 2011 [22] & RCT & 181 & Tamsulosin $0.2 \mathrm{mg}$ & 12 Weeks & $\begin{array}{l}\text { Tamsulosin } \\
0.2 \mathrm{mg}+ \\
\text { tolterodine } \\
2 \mathrm{mg}\end{array}$ & $\begin{array}{l}\text { Tamsulosin, 52.2; } \\
\text { tamsulosin }+ \\
\text { tolterodine, } 53.7\end{array}$ & $\begin{array}{l}\text { IPSS, Qmax, } \\
\text { PVR }\end{array}$ \\
\hline Kim, 2014 [21] & Open-label prospective & 296 & Tamsulosin $0.2 \mathrm{mg}$ & 4 Weeks & None & 58.3 & $\begin{array}{l}\text { IPSS, Qmax, } \\
\text { PVR }\end{array}$ \\
\hline Koh, 2011 [23] & Open-label prospective & 19 & Alfuzocin $10 \mathrm{mg}$ & 12 Weeks & None & 50.4 & $\begin{array}{l}\text { IPSS, Qmax, } \\
\text { PVR }\end{array}$ \\
\hline Lee, 2010 [24] & Open-label prospective & 106 & Tamsulosin $0.2 \mathrm{mg}$ & 8 Weeks & None & 52.9 & $\begin{array}{l}\text { IPSS, Qmax, } \\
\text { PVR }\end{array}$ \\
\hline Lee, 2018 [5] & RCT & 154 & Alfuzosin $10 \mathrm{mg}$ & 8 Weeks & Placebo & $\begin{array}{l}\text { Alfuzosin, 57.4; } \\
\text { placebo, } 57.9\end{array}$ & $\begin{array}{l}\text { AUA-SS, } \\
\text { Qmax, PVR }\end{array}$ \\
\hline Lepor, 1995 [25] & RCT & 29 & Terazosin $10 \mathrm{mg}$ & 6 Weeks & Placebo & $\begin{array}{l}\text { Terazosin, } 60.6 ; \\
\text { placebo, } 62.8\end{array}$ & $\begin{array}{l}\text { AUA-SS, } \\
\text { Qmax }\end{array}$ \\
\hline Low, 2008 [26] & RCT & 80 & Terazosin $10 \mathrm{mg}$ & 14 Weeks & Placebo & NA & $\begin{array}{l}\text { IPSS, Qmax, } \\
\text { PVR }\end{array}$ \\
\hline Pischedda, 2005 [27] & Open-label prospective & 18 & Tamsulosin $0.4 \mathrm{mg}$ & 4 Weeks & None & 49.9 & Qmax, PVR \\
\hline $\begin{array}{l}\text { Pummangura, } \\
2007 \text { [6] }\end{array}$ & RCT & 140 & Tamsulosin $0.2 \mathrm{mg}$ & 4 Weeks & Placebo & $\begin{array}{l}\text { Tamsulosin, } 42.5 \text {; } \\
\text { placebo, } 49.8\end{array}$ & $\begin{array}{l}\text { IPSS, Qmax, } \\
\text { PVR }\end{array}$ \\
\hline
\end{tabular}

Qmax, maximal flow rate; PVR, postvoid residual volume; IPSS, International Prostate Symptom Score; AUASS, American Urological Association Symptom Score; NA, not available; RCT, randomized clinical trial. 
Urinary symptom score

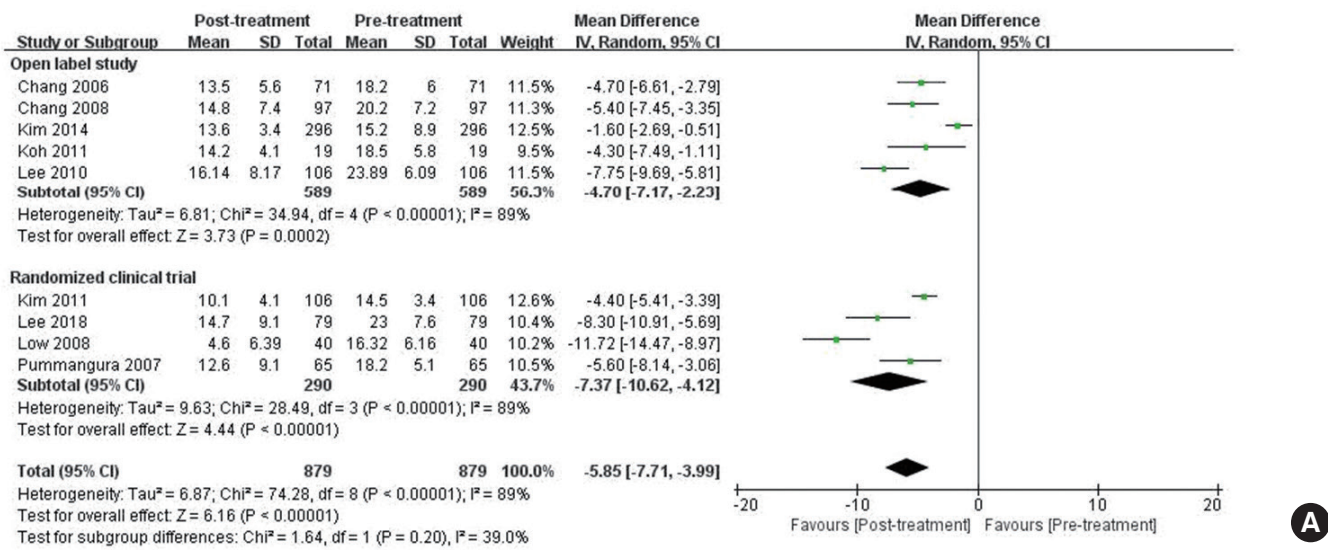

Maximal flow rate

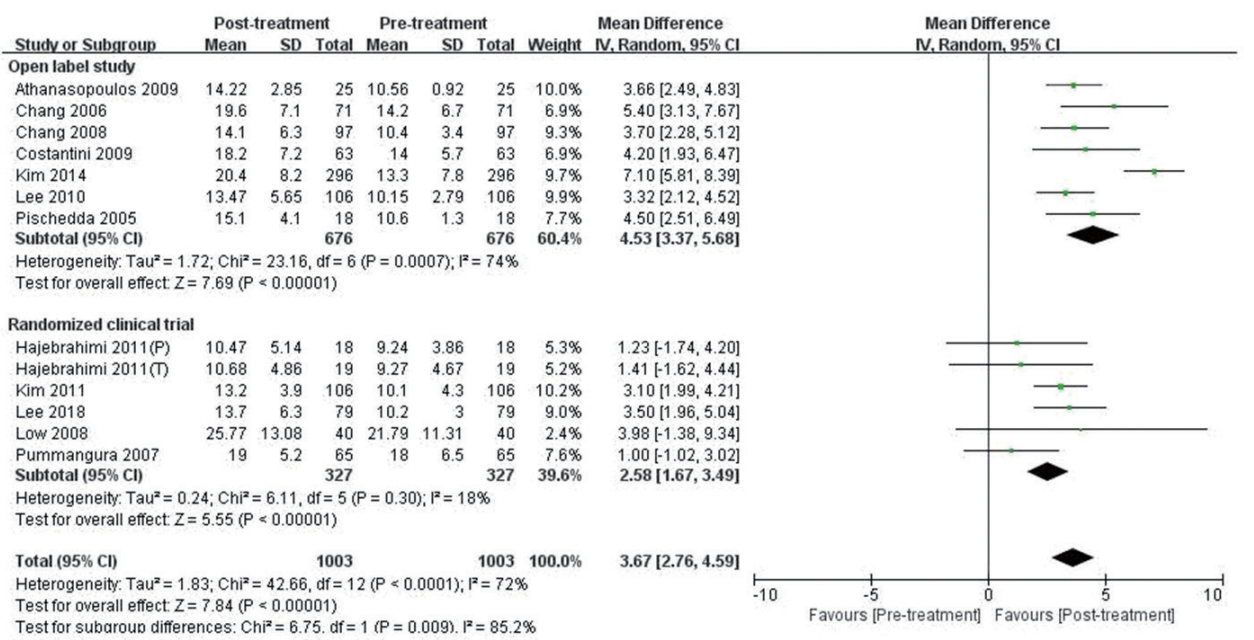

B

Postvoid residual urine

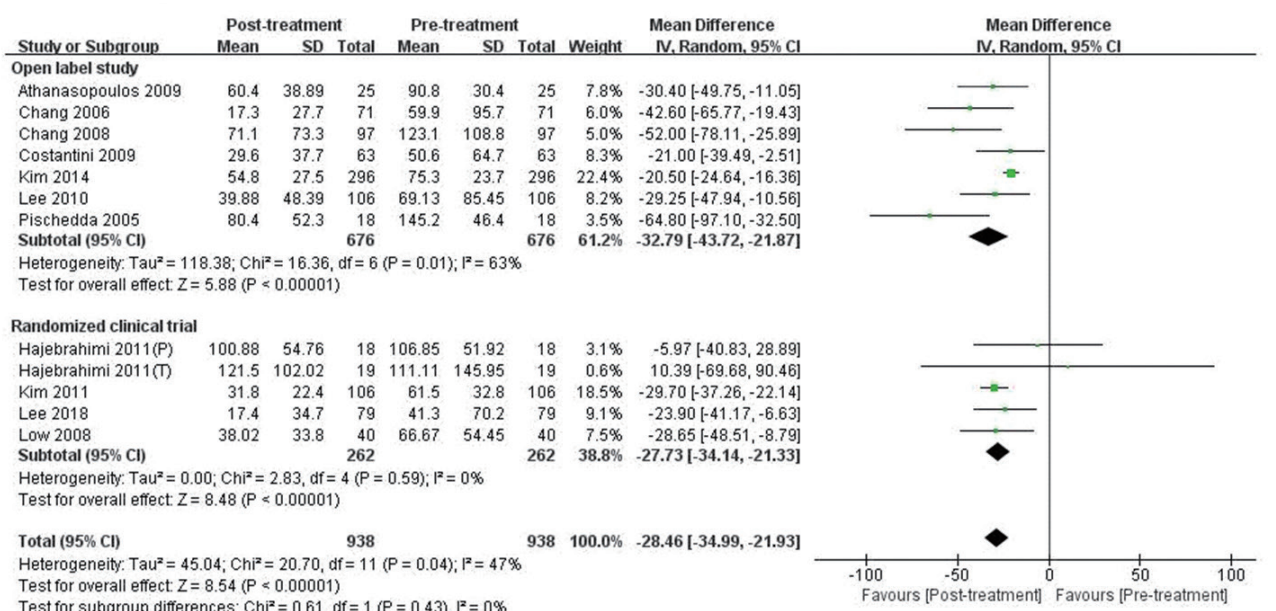

Fig. 2. Forest plots comparing pre-post study outcomes (subgroup-analysis by study design). The evaluated outcomes included urinary symptom score (A), maximal flow rate (B), and postvoid residual urine volume (C). P, prazosin; T, terazosin; SD, standard deviation; CI, confidence interval; df, degrees of freedom. 
ASS. These 2 questionnaires consist of the same 9 questions about incomplete emptying, frequency, intermittency, urgency, weak stream, straining, nocturia, and quality of life due to urinary symptoms (Supplementary Figs. 1, 2).

\section{Comparisons of Pretreatment and Posttreatment Outcomes}

Subgroup analyses were performed by study design and type of a1-blocker (Fig. 2, Supplementary Fig. 3).

\section{Urinary symptom score}

Urinary symptoms score was analyzed in 9 studies with 879 patients (Fig. 2A). Posttreatment outcomes demonstrated statistically significant symptom relief relative to pretreatment (MD,
-5.85 ; 95\% CI, -7.71 to $-3.99, \mathrm{P}<0.00001)$. Heterogeneity was observed among the included studies $\left(\mathrm{I}^{2}=89 \% ; \mathrm{P}<0.00001\right)$.

\section{Qmax}

The analysis of Qmax comprised 13 studies with 1,003 patients (Fig. 2B). Qmax significantly increased following treatment (MD, $3.67 \mathrm{~mL} / \mathrm{sec}$; 95\% CI, 2.76-4.59 mL/sec, P<0.00001). Heterogeneity among the included studies was observed $\left(\mathrm{I}^{2}=72 \% ; \mathrm{P}<0.0001\right)$.

\section{PVR volume}

PVR volume was assessed on the basis of 12 studies with 938 patients (Fig. 2C). Posttreatment PVR values significantly decreased relative to pretreatment values $(\mathrm{MD},-28.46 \mathrm{~mL} ; 95 \%$

Urinary symptom score

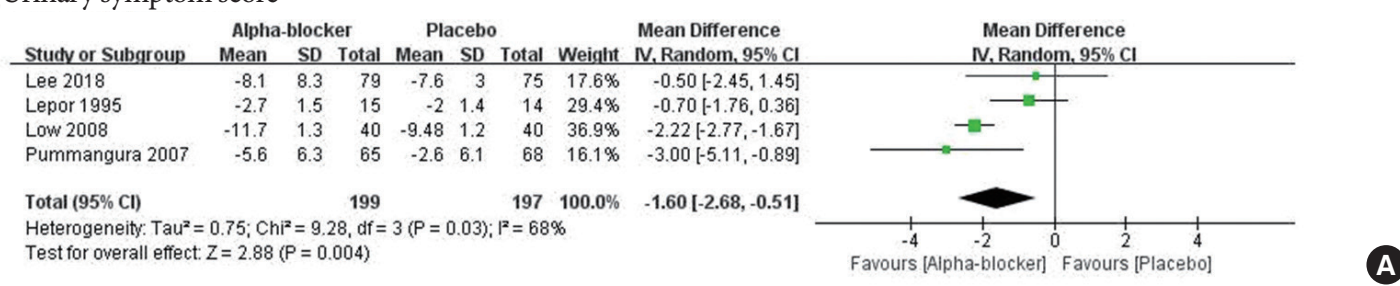

Maximal flow rate

\begin{tabular}{|c|c|c|c|c|c|c|c|c|c|c|}
\hline \multirow[b]{2}{*}{ Studv or Subgroup } & \multicolumn{3}{|c|}{ Alpha-blocker } & \multicolumn{3}{|c|}{ Placebo } & & \multirow{2}{*}{$\begin{array}{l}\text { Mean Difference } \\
\text { IV. Random. } 95 \% \mathrm{Cl}\end{array}$} & \multirow{2}{*}{\multicolumn{2}{|c|}{$\begin{array}{c}\text { Mean Difference } \\
\text { IV. Random. } 95 \% \mathrm{Cl}\end{array}$}} \\
\hline & Mean & SD & Total & Mean & SD & Total & Weight & & & \\
\hline Lee 2018 & 3.7 & 6.6 & 79 & 5.2 & 8.6 & 75 & $10.4 \%$ & $-1.50[-3.93,0.93]$ & & \\
\hline Lepor 1995 & -1 & 3 & 15 & -2 & 2.9 & 14 & $13.4 \%$ & $1.00[-1.15,3.15]$ & & \\
\hline Low 2008 & 3.98 & 2.4 & 40 & 3.85 & 2.1 & 40 & $63.2 \%$ & $0.13[-0.86,1.12]$ & & \\
\hline Pummangura 2007 & 1 & 4.2 & 65 & 1.1 & 8.1 & 68 & $13.0 \%$ & $-0.10[-2.28,2.08]$ & & \\
\hline Total $(95 \% \mathrm{Cl})$ & & & 199 & & & 197 & $100.0 \%$ & $0.05[-0.74,0.83]$ & & \\
\hline $\begin{array}{l}\text { Heterogeneity: Tauz } \\
\text { Test for owerall effect }\end{array}$ & $\begin{array}{l}0.00 ; \mathrm{Cr} \\
\mathrm{Z}=0.12\end{array}$ & $\begin{array}{l}=2.3 \\
=0 .\end{array}$ & $\begin{array}{l}\text { 6, df }= \\
\text { g1) }\end{array}$ & $3(P=t)$ & $0.50)$; & $1^{2}=0 \%$ & & & -2 & 2 \\
\hline
\end{tabular}

Postvoid residual urine

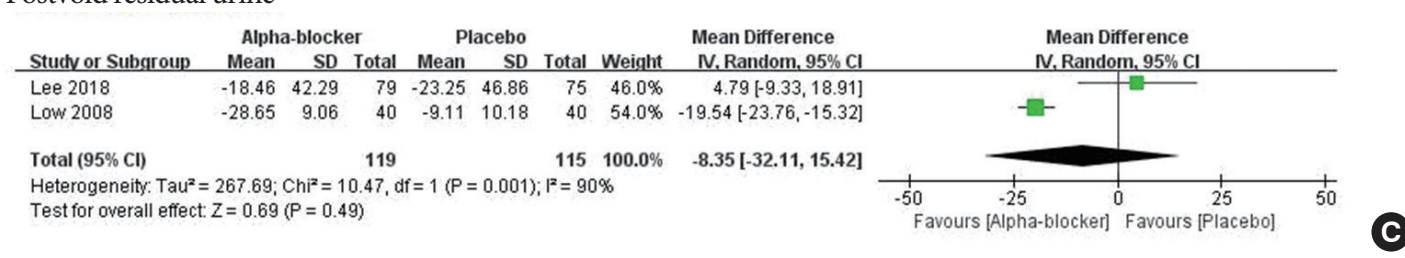

Adverse event

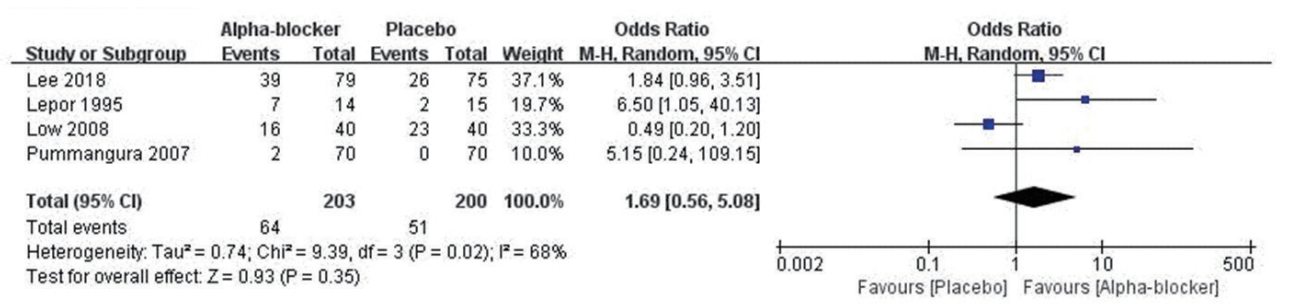

Fig. 3. Forest plots comparing outcomes between al-blocker and placebo groups. Evaluated outcomes included urinary symptom score (A), maximal flow rate (B), residual urine volume (C), and adverse events (D). SD, standard deviation; CI, confidence interval; df, degrees of freedom. 
CI, -34.99 to $-21.93 \mathrm{~mL} ; \mathrm{P}<0.00001)$. Statistical heterogeneity was not observed $\left(\mathrm{I}^{2}=47 \% ; \mathrm{P}=0.04\right)$.

\section{Outcome Comparisons Between A1-Blocker and Placebo Groups}

\section{Urinary symptom score}

Urinary symptoms score was analyzed in 4 studies with 396 patients (Fig. 3A). Statistically significant symptom relief was observed following al-blocker treatment relative to placebo (MD, $-1.60 ; 95 \% \mathrm{CI},-2.68$ to $-0.51 ; \mathrm{P}=0.004)$. Between-study heterogeneity was observed $\left(\mathrm{I}^{2}=68 \% ; \mathrm{P}=0.03\right)$.

\section{Qmax}

The analysis of Qmax comprised 4 studies with 396 patients (Fig. 3B). Treatment with a1-blockers did not significantly alter Qmax relative to placebo (MD, $0.05 \mathrm{~mL} / \mathrm{sec}$; $95 \% \mathrm{CI},-0.75$ to
$0.83 \mathrm{~mL} / \mathrm{sec} ; \mathrm{P}=0.91)$. Heterogeneity among the included studies was not observed $\left(\mathrm{I}^{2}=0 \% ; \mathrm{P}=0.50\right)$.

\section{PVR volume}

PVR volume was analyzed on the basis of 2 studies with 234 patients (Fig. 3C). No significant difference in PVR volume was observed between the al-blocker and placebo groups (MD, $-8.10 \mathrm{~mL} ; 95 \% \mathrm{CI},-32.32$ to $16.12 \mathrm{~mL} ; \mathrm{P}=0.51)$. Between-study heterogeneity was observed $\left(\mathrm{I}^{2}=91 \% ; \mathrm{P}=0.001\right)$.

\section{Adverse events}

Adverse events were reported in 4 studies with 403 patients (Fig. 3D). No significant difference in adverse events was observed between the al-blocker and placebo groups (OR, 1.69; 95\% CI, 0.56-5.08, $\mathrm{P}=0.35)$. Between-study heterogeneity was observed $\left(\mathrm{I}^{2}=68 \% ; \mathrm{P}=0.02\right)$.
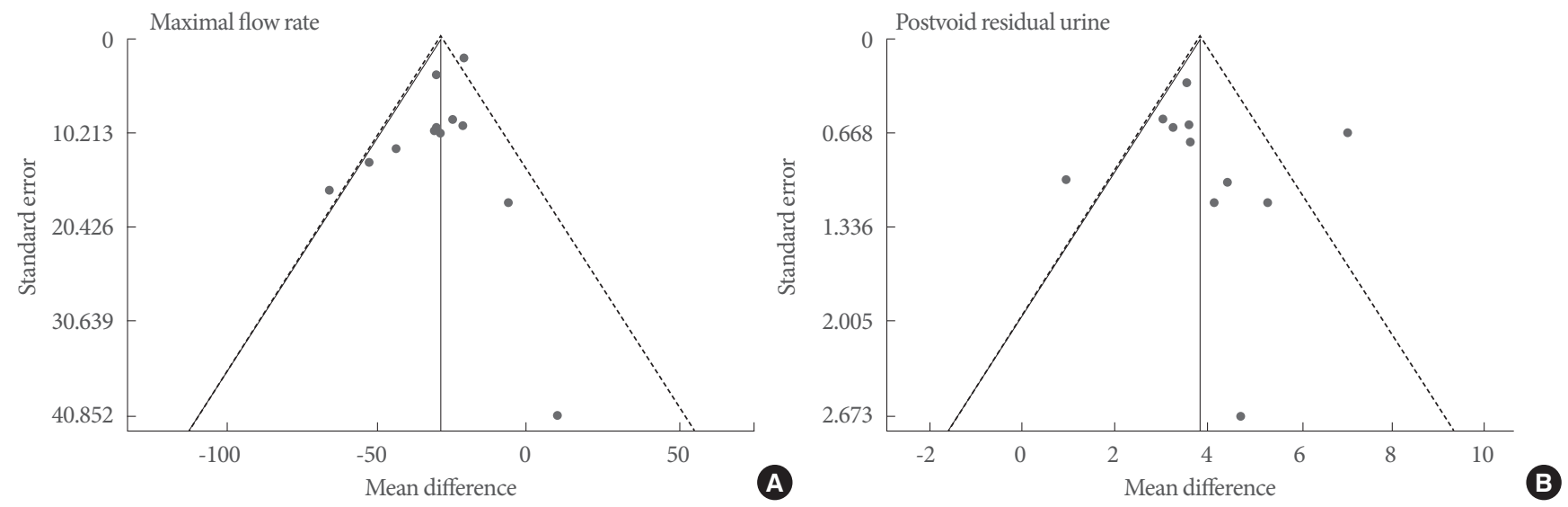

Fig. 4. Publication bias analysis. Funnel plots for maximal flow rate (A) and postvoid residual urine volume (B).

Table 2. Downs and black scale for quality assessment of non-RCT and single-arm studies

\begin{tabular}{|c|c|c|c|c|c|c|}
\hline \multirow[b]{2}{*}{ Study } & \multirow[b]{2}{*}{ Reporting } & \multirow[b]{2}{*}{ External validity } & \multicolumn{2}{|c|}{ Internal validity } & \multirow[b]{2}{*}{ Power } & \multirow[b]{2}{*}{ Total } \\
\hline & & & Bias & $\begin{array}{l}\text { Confounding } \\
\text { (selection bias) }\end{array}$ & & \\
\hline Athanasopoulos, 2009 [16] & 7 & 1 & 3 & 1 & 1 & 13 \\
\hline Chang, 2006 [17] & 7 & 1 & 4 & 1 & 2 & 15 \\
\hline Chang, 2008 [18] & 7 & 1 & 3 & 1 & 2 & 14 \\
\hline Costantini, 2009 [19] & 7 & 1 & 3 & 1 & 2 & 14 \\
\hline Kim, $2014[21]$ & 5 & 1 & 3 & 1 & 2 & 12 \\
\hline Koh, 2011 [23] & 7 & 1 & 3 & 1 & 1 & 13 \\
\hline Lee, $2010[24]$ & 7 & 1 & 3 & 1 & 2 & 14 \\
\hline Pischedda, 2005 [27] & 6 & 1 & 3 & 1 & 1 & 12 \\
\hline
\end{tabular}

RCT, randomized clinical trial. 


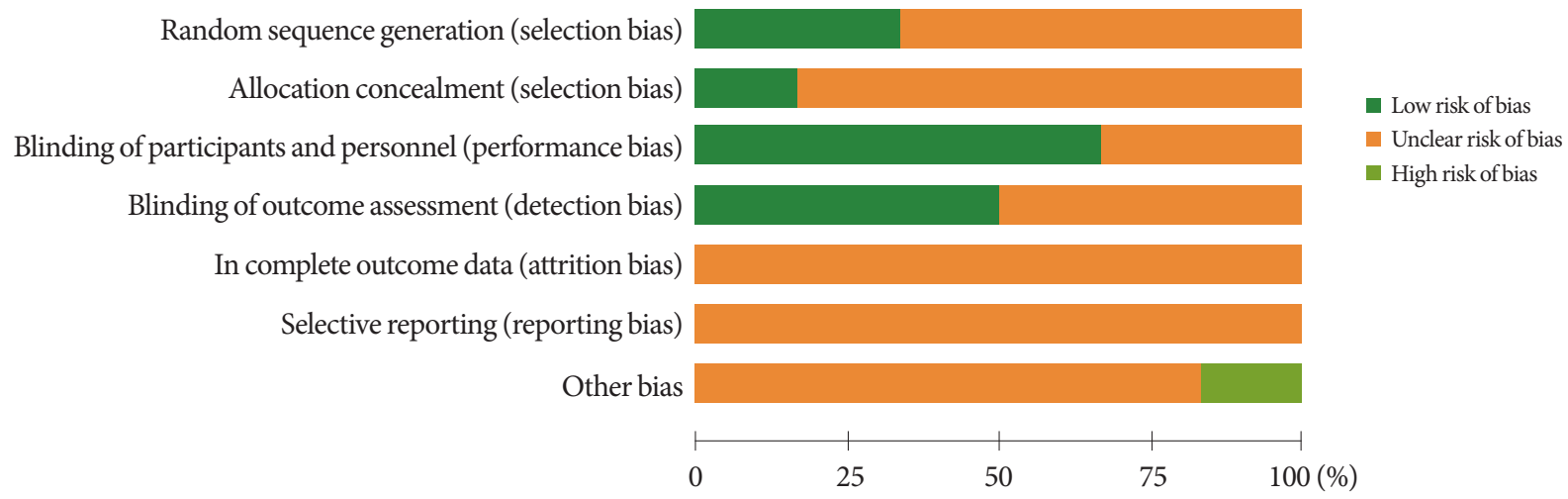

Fig. 5. Risk of bias assessment graph. Risk of bias was assessed using the Cochrane Risk of Bias Tool.

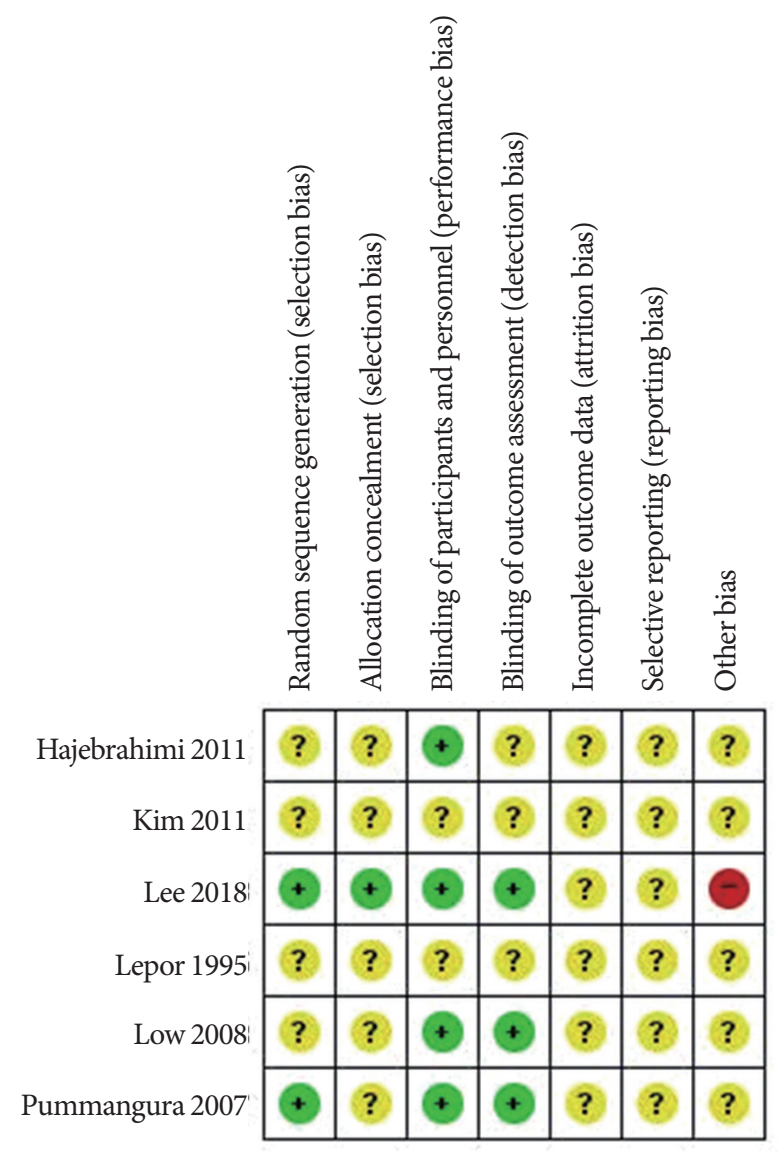

Fig. 6. Study-specific bias risk. Risk of bias was assessed using the Cochrane Risk of Bias Tool. A green plus sign indicates a low risk of bias, a yellow question mark indicates an unclear risk of bias, and a red minus sign indicates a high risk of bias.

\section{Sensitivity Analysis}

A sensitivity analysis was performed using sequential exclusion of studies to evaluate the effect of each study on the overall results of the meta-analysis. The exclusion of any single study did not result in statistically significant changes in the results (data not shown). The results were statistically reliable.

\section{Publication Bias, Quality Assessment, and Qualitative Risk of Bias}

The funnel plot analysis of publication bias of the pre-post studies demonstrated a certain degree of symmetry (Fig. 4). The Egger test revealed no statistical evidence of publication bias in the meta-analysis of Qmax and PVR volume $(\mathrm{P}=0.77$ and $\mathrm{P}=0.18$, respectively).

The Downs and Black scale was utilized to assess the quality of 8 prospective trials using the reporting, external validity, bias, confounding, and power assessment categories (Table 2). The Downs and Black scores of the evaluated studies ranged from 12 to 15 . The risk of bias graph and assessment of RCTs are summarized in Figs. 5 and 6. One study did demonstrate a statistically high risk of other biases (early stop due to low recruitment and enrollment rate).

The results of the GRADE quality assessment for direct evidence of each comparison are shown in Tables 3-5. Of the 10 comparisons, certainty was moderate in 5 and low in 5 .

\section{DISCUSSION}

Large-population studies have indicated that LUTS are highly prevalent in women and men over 40 years of age [28]. Storage LUTS, including urinary incontinence, are more prevalent in women. Conversely, voiding LUTS are more common in men. However, women also suffer from voiding LUTS despite the absence of obvious anatomic obstructions, such as benign prostatic obstructions seen in men. In men with benign prostatic hyperplasia, a1-blockers relieve LUTS via smooth muscle relax- 

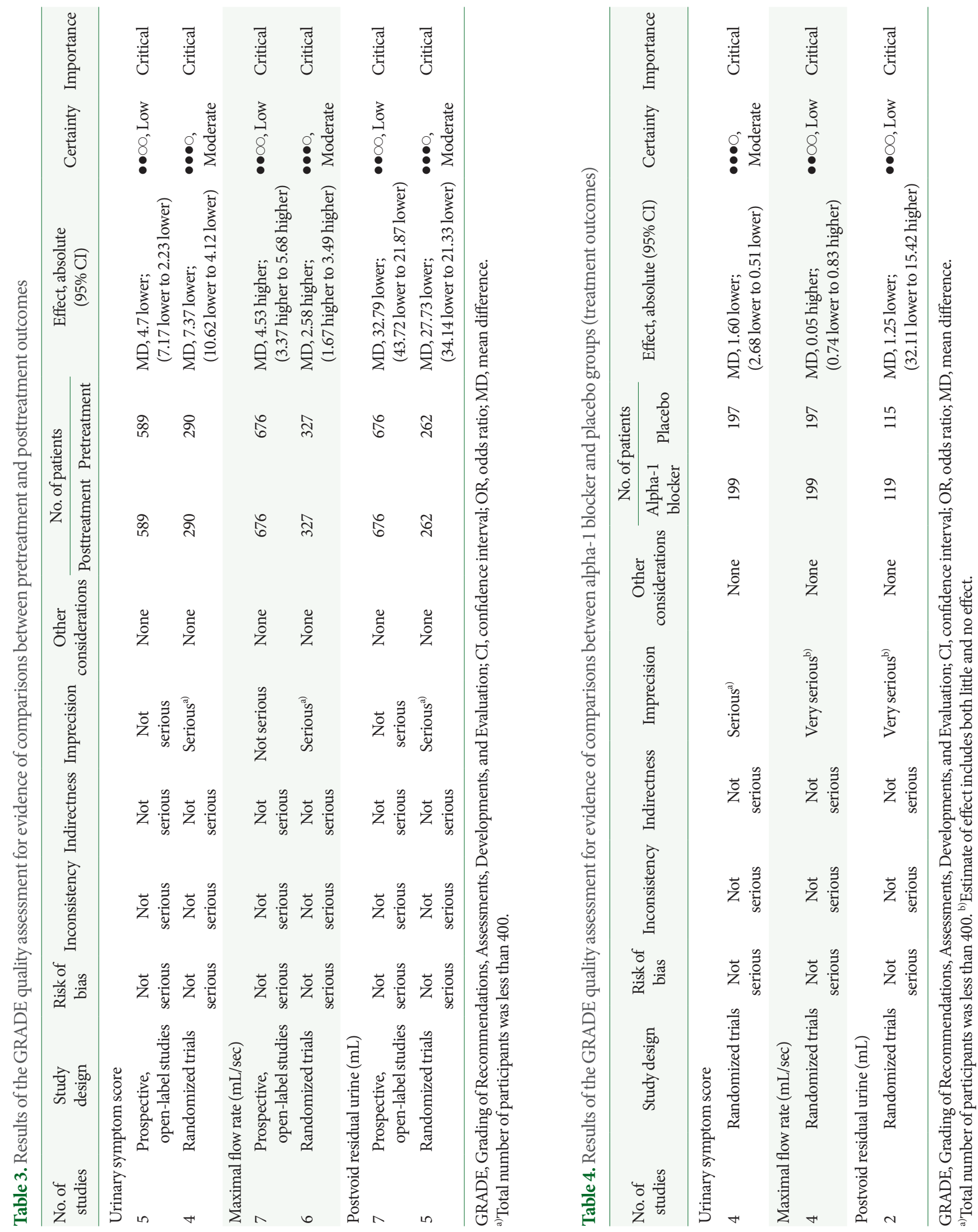


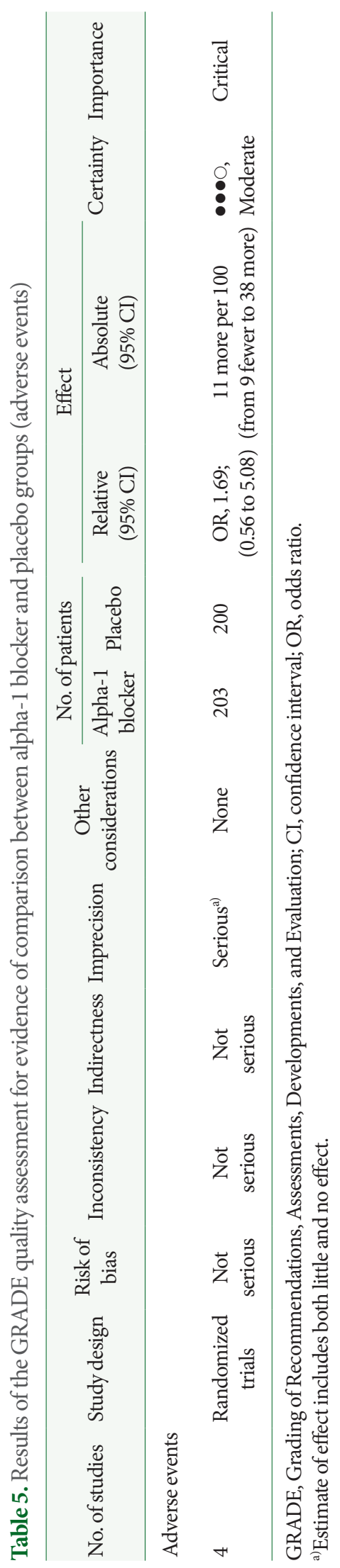

ation in the prostate and the bladder neck. Thus, many clinicians have prescribed similar treatments to women with LUTS based on the assumption that a1-blockers will similarly affect the female bladder neck. Some open-label prospective trials $[16-19,21,23,24,27]$ and RCTs $[5,6,20,22,25,26]$ have examined the effect of al-blockers on female voiding dysfunction. However, the outcomes of these studies have not been consistent. The lack of well-designed RCTs with large study populations further prevents the establishment of a consensus on the use of a1-blockers for LUTS in women. Therefore, the authors in the present study performed a systematic review and meta-analysis to assess the evidence and to provide more information regarding the efficacy of $\alpha 1$-blockers in the treatment of female LUTS.

Our meta-analysis demonstrated that a1-blockers have beneficial effects on female LUTS. Our study comprised 2 analyses: a comparison of urinary symptom scores and urodynamic parameters before and after $\alpha 1$-blocker treatment in 8 prospective, open-label studies and 5 RCTs, and the comparison of the same variables following a1-blocker and placebo treatments in 4 RCTs. The first analysis indicated that al-blockers are effective in reducing urinary symptom scores (-5.85 points), increasing Qmax $(+3.67 \mathrm{~mL} / \mathrm{sec})$, and decreasing PVR urine volume $(-28.46 \mathrm{~mL})$. Recent studies have suggested that a1-blockers may provide an effective treatment effect for female functional bladder outlet obstruction. Kumar et al. [29] reported that 50\% of women with functional bladder outlet obstruction experienced improvements in urinary symptoms, Qmax, and PVR after treatment with $\alpha 1$-blocker therapy alone. Yamanish et al. [30] also reported that female patients with detrusor underactivity showed improvements in the total IPSS (-6.3 points) and PVR volume ( $48 \mathrm{~mL}$ ) after 4 weeks of a1-blocker treatment, and that storage and voiding symptom scores were reduced.

The second analysis demonstrated that $\alpha 1$-blockers are more effective in reducing urinary symptoms than placebo, but with an MD of only 1.6 points. Furthermore, no significant differences in Qmax and PVR volume between the a1-blocker and the placebo groups were observed. Zhang et al. [31] previously performed a meta-analysis comparing the effects of tamsulosin and various controls (placebo, anticholinergics, or combination therapy) in female LUTS patients. Our meta-analysis included studies using not only tamsulosin, but also other a1-blockers, such as alfuzosin and terazosin. In addition, only placebo control arms were included in our analysis. Furthermore, in contrast to Zhang and colleagues, the authors in the present study also added prospective open-label studies to compare pre- and 
posttreatment clinical variables in our analysis of the effects of a1-blockers on female LUTS.

Although our meta-analysis indicated positive effects of $\alpha 1$ blockers on both subjective and objective variables in the treatment of LUTS, we recommend caution in the interpretation of the results. Bias is likely in simple pre-post comparisons in clinical studies of voiding dysfunction. For example, as participants become accustomed to the test method (i.e., uroflowmetry), the results of the subsequent tests can improve. A strong behavioral factor has been observed in the placebo response of LUTS patients, as revealed by voiding diaries that make patients aware of their voiding habits, as well as of the timing and quantity of fluid intake [32]. In addition, significant placebo effects cannot be avoided in open-label studies. Thus, the clinical implications of our pre-post study meta-analysis are limited.

In contrast, the second meta-analysis, targeting placebo-controlled RCTs, has more important clinical implications. This meta-analysis, which demonstrated a significant effect of a1blockers on urinary symptom relief, suggests that a1-blockers should be considered for the treatment of women suffering from LUTS. However, a <2-point MD in urinary symptom scores and an absence of significant differences in objective measurements were observed between the a1-blocker and placebo groups. These findings may be partly explained by the placebo effect. The involvement of neurotransmitters in the urination process can account for the LUTS placebo response, at least with respect to the subjective outcome. A placebo-induced dopamine release in LUTS patients has been hypothesized to improve bladder function [33]. Several studies have examined the specific factors influencing the placebo response in LUTS patients. Placebo therapy rapidly produces a significant improvement in Qmax and relieves the symptoms of benign prostatic hyperplasia, with fading beneficial effects remaining even after 2 years [34]. Another study also suggested that the placebo effect is often rapid, but declines over time [35]. In the present meta-analysis, the treatment periods in the RCTs ranged from 4 to 12 weeks. Thus, it is possible that the peak placebo effect was observed in the urinary symptom score and Qmax measurements due to the short follow-up period. Nickel [34] also demonstrated that placebo responses were higher in patients with small or normal prostates. Assuming that female LUTS are more similar to LUTS in men with smaller prostates, a stronger placebo effect in women may further explain the observed limited effect of a1-blockers on female LUTS.

The authors in the present study compared adverse event rates between al-blockers and placebo in the studies that reported safety outcomes for the al-blockers and found no statistically significant difference in the adverse event rate of the a1blockers compared to placebo $[5,6,25,26]$. The side effects of a1-blockers reported in the studies were dizziness, headache, asthenia, GI discomfort, and edema. The most common adverse events were dizziness and headache. Although the results of this study showed no difference in adverse events between a1-blockers and placebo, clinicians should always use caution regarding side effects while assessing a patient's condition.

Among the RCTs analyzed, Lee et al. [5] applied relatively strict inclusion criteria (AUASS $\geq 15$ and Qmax $<15 \mathrm{~mL} / \mathrm{sec}$ and/or PVR volume $>150 \mathrm{~mL}$ ). However, the other 3 RCTs used very simple selection criteria (IPSS $>8$ ), with no specific cutoffs for Qmax or PVR volume $[6,25,26]$. Such broad criteria may not select for $\alpha 1$-blocker-responsive candidates. The metaanalysis was further limited by the small sample sizes and the methodological quality of the included RCTs. Moreover, between-trial differences in al-blockers and treatment periods also likely affected the results. Thus, high-quality RCTs, with large sample sizes, adequately defined study participants, and long-term treatment and follow-up, are required to overcome these limitations and to draw more reliable conclusions.

In conclusion, our results suggest that a1-blockers may be effective in the treatment of female LUTS. However, certain limitations of the study, which could have led to inevitable bias, may have masked the effects of al-blockers in the treatment of female LUTS. Thus, the results of this study should be interpreted with caution. Although a1-blockers are effective for treating female LUTS patients, the effect of al-blockers on female LUTS should be assessed according to the underlying cause. In addition, the role of al-blockers in combination therapy with other drugs should also be investigated.

\section{SUPPLEMENTARY MATERIALS}

Supplementary Figs. 1-3 can be found via https://doi.org/10. 5213/inj.1836188.094.

\section{AUTHOR CONTRIBUTION STATEMENT}

- Full access to all the data in the study and takes responsibility for the integrity of the data and the accuracy of the data analysis: $D K K, K S C$

-Study concept and design: DKK, KSC 
- Acquisition of data: DKK, JYL, KSC

- Analysis and interpretation of data: $D K K, J H J$

- Drafting of the manuscript: DKK, KSC

- Critical revision of the manuscript for important intellectual content: DKK, KSC

- Statistical analysis: $D K K, J H K, C H H$

- Administrative, technical, or material support: DKK, YSH

- Study supervision: KSC

\section{REFERENCES}

1. Oelke M, Bachmann A, Descazeaud A, Emberton M, Gravas S, Michel MC, et al. EAU guidelines on the treatment and follow-up of non-neurogenic male lower urinary tract symptoms including benign prostatic obstruction. Eur Urol 2013;64:118-40.

2. Haylen BT, Freeman RM, Swift SE, Cosson M, Davila GW, Deprest J, et al. An International Urogynecological Association (IUGA)/International Continence Society (ICS) joint terminology and classification of the complications related directly to the insertion of prostheses (meshes, implants, tapes) and grafts in female pelvic floor surgery. Neurourol Urodyn 2011;30:2-12.

3. Haylen BT, Krishnan S, Schulz S, Verity L, Law M, Zhou J, et al. Has the true prevalence of voiding difficulty in urogynecology patients been underestimated? Int Urogynecol J Pelvic Floor Dysfunct 2007;18:53-6.

4. Patel R, Nitti V. Bladder outlet obstruction in women: prevalence, recognition, and management. Curr Urol Rep 2001;2:379-87.

5. Lee YS, Lee KS, Choo MS, Kim JC, Lee JG, Seo JT, et al. Efficacy of an alpha-blocker for the treatment of nonneurogenic voiding dysfunction in women: an 8-week, randomized, double-blind, placebo-controlled trial. Int Neurourol J 2018;22:30-40.

6. Pummangura N, Kochakarn W. Efficacy of tamsulosin in the treatment of lower urinary tract symptoms (LUTS) in women. Asian J Surg 2007;30:131-7.

7. Groutz A, Blaivas JG. Non-neurogenic female voiding dysfunction. Curr Opin Urol 2002;12:311-6.

8. Shim SR, Kim JH, Chang IH, Shin IS, Hwang SD, Kim KH, et al. Is Tamsulosin $0.2 \mathrm{mg}$ effective and safe as a first-line treatment compared with other alpha blockers?: A meta-analysis and a moderator focused study. Yonsei Med J 2016;57:407-18.

9. Moher D, Shamseer L, Clarke M, Ghersi D, Liberati A, Petticrew M, et al. Preferred reporting items for systematic review and metaanalysis protocols (PRISMA-P) 2015 statement. Syst Rev 2015;4:1.

10. Liberati A, Altman DG, Tetzlaff J, Mulrow C, Gøtzsche PC, Ioannidis JP, et al. The PRISMA statement for reporting systematic re- views and meta-analyses of studies that evaluate health care interventions: explanation and elaboration. PLoS Med 2009;6:e1000100.

11. Higgins JP, Altman DG, Gøtzsche PC, Jüni P, Moher D, Oxman $\mathrm{AD}$, et al. The Cochrane Collaboration's tool for assessing risk of bias in randomised trials. BMJ 2011;343:d5928.

12. Downs SH, Black N. The feasibility of creating a checklist for the assessment of the methodological quality both of randomised and non-randomised studies of health care interventions. J Epidemiol Community Health 1998;52:377-84.

13. Luo D, Wan X, Liu J, Tong T. Optimally estimating the sample mean from the sample size, median, mid-range, and/or mid-quartile range. Stat Methods Med Res 2018;27:1785-805.

14. Wan X, Wang W, Liu J, Tong T. Estimating the sample mean and standard deviation from the sample size, median, range and/or interquartile range. BMC Med Res Methodol 2014;14:135.

15. DerSimonian R, Kacker R. Random-effects model for meta-analysis of clinical trials: an update. Contemp Clin Trials 2007;28:10514.

16. Athanasopoulos A, Gyftopoulos K, Giannitsas K, Perimenis P. Effect of alfuzosin on female primary bladder neck obstruction. Int Urogynecol J Pelvic Floor Dysfunct 2009;20:217-22.

17. Chang HS, Park CH, Kwon TG, Kim DY, Oh TH, Jung JI, et al. Efficacy of tamsulosin $0.2 \mathrm{mg} /$ day in female patients with lower urinary tract symptoms. J Korean Continence Soc 2006;10:140-6.

18. Chang SJ, Chiang IN, Yu HJ. The effectiveness of tamsulosin in treating women with voiding difficulty. Int J Urol 2008;15:981-5.

19. Costantini E, Lazzeri M, Bini V, Zucchi A, Fioretti F, Frumenzio E, et al. Open-label, longitudinal study of tamsulosin for functional bladder outlet obstruction in women. Urol Int 2009;83:311-5.

20. Hajebrahimi S, Asrbadr YA, Azaripour A, Sadeghi-Bazargani H. Effect of tamsulosin versus prazosin on clinical and urodynamic parameters in women with voiding difficulty: a randomized clinical trial. Int J Gen Med 2011;4:35-9.

21. Kim SO, Choi HS, Kwon D. The al adrenoceptor antagonist tamsulosin for the treatment of voiding symptoms improves nocturia and sleep quality in women. Urol J 2014;11:1636-41.

22. Kim SO, Hwang EC, Oh KJ, Kwon D, Park K, Ryu SB. Efficacy and safety of combined therapy with tamsulosin and tolterodine in female patients with a maximal flow rate less than $12 \mathrm{ml} / \mathrm{s}$. Int Urogynecol J 2011;22:1287-91.

23. Koh JS, Kim SJ, Kim HS, Kim JC. Comparison of alpha-blocker, extracorporeal magnetic stimulation alone and in combination in the management of female bladder outlet obstruction. Int Urogynecol J 2011;22:849-54.

24. Lee KS, Han DH, Lee YS, Choo MS, Yoo TK, Park HJ, et al. Effica- 
cy and safety of tamsulosin for the treatment of non-neurogenic voiding dysfunction in females: a 8-week prospective study. J Korean Med Sci 2010;25:117-22.

25. Lepor H, Theune C. Randomized double-blind study comparing the efficacy of terazosin versus placebo in women with prostatismlike symptoms. J Urol 1995;154:116-8.

26. Low BY, Liong ML, Yuen KH, Chee C, Leong WS, Chong WL, et al. Terazosin therapy for patients with female lower urinary tract symptoms: a randomized, double-blind, placebo controlled trial. J Urol 2008;179:1461-9.

27. Pischedda A, Pirozzi Farina F, Madonia M, Cimino S, Morgia G. Use of alpha1-blockers in female functional bladder neck obstruction. Urol Int 2005;74:256-61.

28. Coyne KS, Sexton CC, Thompson CL, Milsom I, Irwin D, Kopp ZS, et al. The prevalence of lower urinary tract symptoms (LUTS) in the USA, the UK and Sweden: results from the Epidemiology of LUTS (EpiLUTS) study. BJU Int 2009;104:352-60.

29. Kumar A, Mandhani A, Gogoi S, Srivastava A. Management of functional bladder neck obstruction in women: use of alpha-blockers and pediatric resectoscope for bladder neck incision. J Urol
1999;162:2061-5.

30. Yamanishi T, Yasuda K, Kamai T, Tsujii T, Sakakibara R, Uchiyama $\mathrm{T}$, et al. Combination of a cholinergic drug and an alpha-blocker is more effective than monotherapy for the treatment of voiding difficulty in patients with underactive detrusor. Int J Urol 2004;11:8896.

31. Zhang HL, Huang ZG, Qiu Y, Cheng X, Zou XQ, Liu TT. Tamsulosin for treatment of lower urinary tract symptoms in women: a systematic review and meta-analysis. Int J Impot Res 2017;29:148-56.

32. Abrams P. Managing lower urinary tract symptoms in older men. BMJ 1995;310:1113-7.

33. van Leeuwen JH, Castro R, Busse M, Bemelmans BL. The placebo effect in the pharmacologic treatment of patients with lower urinary tract symptoms. Eur Urol 2006;50:440-52.

34. Nickel JC. Placebo therapy of benign prostatic hyperplasia: a 25-month study. J Urol 1998;160:1584-5.

35. Hauptman J, Lucas C, Boldrin MN, Collins H, Segal KR. Orlistat in the long-term treatment of obesity in primary care settings. Arch Fam Med 2000;9:160-7. 